\title{
BIOKONVERSI KULIT KOPI MENJADI PUPUK KOMPOS PADA KELOMPOK TANI PANGESTU RAKYAT KABUPATEN REJANG LEBONG
}

\author{
Deni Agus Triawan, Charles Banon, dan Morina Adfa \\ Fakultas Matematika dan Ilmu Pengetahuan Alam, Universitas Bengkulu \\ E-mail : deni.agustriawan@unib.ac.id
}

\begin{abstract}
ABSTRAK
Biokonversi limbah kulit kopi menjadi pupuk kompos bertujuan untuk meningkatkan nilai guna dan bahkan dapat bernilai ekonomi limbah kulit kopi. Pengomposan didasarkan pada proses penguraian bahan organik yang terjadi secara alami. Proses penguraian dioptimalkan sedemikian rupa sehingga pengomposan dapat berjalan dengan lebih cepat dan efisien. Tujuan tersebut dicapai melalui beberapa tahapan diantaranya sosialisasi dan penyampaian informasi dan pengetahuan kepada masyarakat tentang biokonversi limbah kulit kopi menjadi pupuk kompos. Penyampaian informasi dilakukan dengan metode ceramah dan pembagian leaflet tentang biokonversi limbah kulit kopi menjadi kompos dan dilanjutkan dengan diskusi dan tanya jawab seputar kegiatan. Selanjutnya dilakukan kegiatan praktek pembuatan kompos dari limbah kulit kopi dengan komposisi bahan baku 80\% limbah kulit kopi, 10\% kotoran sapi dan 10 dedak/sekam padi. Hasil proses pembuatan kompos dari limbah kulit kopi dapat dilihat pada bulan kedua setelah kegiatan dilaksanakan. indikator terbentuknya pupuk kompos adalah warna kompos menghitam, tekstur yang lembut, mudah hancur dan rapuh. Pupuk yang sudah jadi siap untuk diaplikasikan pada lahan kebun untuk berbagai jenis tanaman. Pada masyarakat kelompok tani Pangestu Rakyat, pupuk yang dihasilkan diaplikasikan ke lahan kebun kopi dan kebun sayuran.
\end{abstract}

Kata Kunci: Kulit kopi, EM-4, pupuk organic

\section{PENDAHULUAN}

Berdasarkan data tahun 2016, produksi kopi Kabupaten Rejang Lebong pertahun mencapai 13.402 ton yang tersebar di 15 kecamatan dengan luasan areal perkebunan kopi rakyat lebih kurang 21.635 hektar (Antara Bengkulu, 2016). Produksi ini selanjutnya dipasarkan ke sejumlah daerah seperti ke Kota Bengkulu, kemudian Jambi, Lampung, Palembang, Medan dan lainnya. Selama ini kopi menjadi salah satu sumber mata pecaharian utama masyarakat di Kabupaten Rejang Lebong.

$$
\text { Proses pengolahan kopi di }
$$

Provinsi Bengkulu terutama di Desa Baru Manis Kecamatan Berman Ulu umumnya dilakukan secara natural (dry process). Proses ini termasuk teknik paling tua yang ada dalam sejarah proses pengolahan kopi. Setelah dipanen, ceri kopi akan ditebarkan di atas permukaan terpal/alas lain dan 
dijemur di bawah sinar matahari. Ketika dijemur di bawah matahari, biji-biji kopi ini harus dibolak-balik secara berkala agar biji kopi mengering secara merata, dan untuk menghindari jamur/pembusukan. Setelah buah kopi mengering, proses pengupasan kulit dilakukan dengan mesin pengupas sehigga dengan mudah biji dan kulit kopi dapat terpisah. Dalam proses pengolahan buah kopi tersebut dihasilkan limbah kulit kopi yang cukup banyak yakni sekitar $40 \%$ - 50\% (Afrizon, 2015).

Berdasarkan informasi dari Kelompok Tani Pangestu Rakyat Desa Baru Manis, Bermani Ulu, Rejang Lebong, penanganan limbah organik kulit kopi oleh petani sejauh ini adalah dengan menumpuk limbah kulit kopi di pekarangan atau dibakar. Masyarakat belum sepenuhnya mengetahui bahwa kulit kopi tersebut dapat dimanfaatkan lebih lanjut menjadi produk yang bernilai guna bahkan bernilai ekonomi. Pada tahun 2015, Balai Pengkajian Teknologi Pertanian (BPTP) Bengkulu telah melakukan kajian potensi kulit kopi sebagai bahan baku pupuk kompos dengan tujuan mengetahui efektifitas dan kualitas produk kompos dari kulit kopi. Hasil penelitian tersebut menunjukkan bahwa kandungan nutrient kompos kulit kopi sesuai dengan SNI 19-7030-2004 tentang standar kualitas kompos dengan komposisi campuran $80 \%$ limbah kulit kopi, 10\% kotoran sapi dan 10 dedak/sekam padi (Afrizon, 2015)

Pada prinsipnya, pengembangan pengolahan limbah organik dengan teknologi pengomposan didasarkan pada proses penguraian bahan organik yang terjadi secara alami. Proses penguraian dioptimalkan sedemikian rupa sehingga pengomposan dapat berjalan dengan lebih cepat dan efisien. Pengoptimalan pengomposan dapat dilakukan dengan bantuan bakteri pengompos (Agus et al, 2014). Bakteri pengompos dapat dibeli dengan mudah melalui took pertanian atau secara online seperti Promi, Orga Dec, Super Dec, BioPos, EM-4 dan lainnya. Selain itu komposter juga dapat dibuat sendiri misalnya dengan kotoran hewan atau bahan lainnya (Wandhira et al, 2013 \& Nurlianti et al, 2018).

Pengomposan aerob merupakan proses pengomposan bahan organik dengan menggunakan $\mathrm{O}_{2}$. Hasil akhir dari pengomposan aerob merupakan produk metabolisme biologi berupa $\mathrm{CO}_{2}, \mathrm{H}_{2} \mathrm{O}$, panas, unsur hara, dan sebagian humus. Hasil akhir dari 
pengomposan anaerob terutama berupa

$\mathrm{CH}_{4}$ dan $\mathrm{CO}_{2}$ dan sejumlah hasil antara; timbul bau busuk karena adanya $\mathrm{H}_{2} \mathrm{~S}$ dan sulfur organik seperti merkaptan (Gaur, 1982 \& Haug, 1980).

Teknologi ini menjadi sangat penting bagi masyarakat untuk memanfaatkan limbah kulit kopi yang selama ini belum termanfaatkan dengan baik. Pengelolaan limbah organik (kulit kopi) dengan metode pengomposan ini memiliki beberapa keunggulan diantaranya meningkatkan nilai guna limbah menjadi pupuk organik dan bahkan dapat bernilai ekonomi jika dikembangkan dalam volume yang lebih besar. Dengan alasan tersebut, kegiatan biokonversi limbah kulit kopi menjadi pupuk kompos penting untuk dilakukan mengingat sampai saat ini teknologi pengomposan ini masih belum diterapkan oleh masyarakat petani kopi di kelompok mitra dan di Kabupaten Rejang Lebong pada umumnya.

\section{METODE PELAKSANAAN}

Kegiatan pengabdian kepada masyarakat dilakukan pada masyarakat Kelompok Tani Pangestu Rakyat Desa Baru Manis Kecamatan Bermani Ulu Kabupaten Rejang Lebong dengan metode sebagai berikut :
1. Penyampaian informasi, diskusi dan tanya jawab dengan tujuan meningkatkan pemahaman masyarakat tentang biokonversi limbah kulit kopi menjadi pupuk kompos serta kegunaan dari produk tersebut dan nilai jualnya. Kegiatan ini dimulai dengan ceramah dan diskusi tentang proses pengomposan dan teknologi yang dapat diterapkan melalui pembagian handout pada kelompok tani. Setelah mitra memahami teknologi dan proses biokonversi tersebut, kegiatan dilanjutkan dengan pelatihan dan pembuatan produk secara intensif.

\section{Pelatihan biokonversi limbah} kulit kopi menjadi pupuk

\section{kompos}

Proses pembuatan kompos dari kulit kopi diawali dengan pembutan cetakan bambu dengan ukuran lebar 2 meter x 1 meter dan tinggi 0.5 meter. Setelah cetakan/tempat pengomposan jadi, pembuatan kompos dilanjutkan dengan memasukkan kulit kopi yang telah dicampur dengan kotoran sapi, sekam padi $10 \%$ dan activator EM4. Komposisi campuran ini adalah kulit kopi 
$80 \%$, kotoran sapi $10 \%$ dan activator EM4 secukupnya2. Penambahan kotoran sapi dan aktivator dimaksudkan untuk mempercepat proses pengomposan (Hartatik et al, 2012). Proses pencampuran ini sebaiknya merata agar proses pengomposan lebih maksimal. Secara rinci adalah sebagi berikut :

a. Kulit buah kopi dicampur dengan pupuk kandang, kemudian ditaburi dolomit, gula serta disiram dengan decomposer dan juga air

b. Semua bahan tersebut dibuat berlapis-lapis sampai tinggi tumpukan di dalam bak/cetakan.

c. Setelah proses berlangsung, suhu dalam bak naik hingga kurang lebih 50 Celcius, tapi setelah itu suhu akan turun lagi,

d. Setiap 1 minggu sekali dipantau dan jika ternyata terlalu kering maka dilakukan penyiraman

e. Setelah 4 - 5 bulan kompos telah siap panen. Kompos yang telah jadi ditandai dengan warna hitam kecoklatan.

f. Kompos siap dikemas atau langsung diapllikasikan g. Kompos yang sudah jadi akan diaplikasikan pada lahan kebun dan sebagian dikemas untuk dijual.

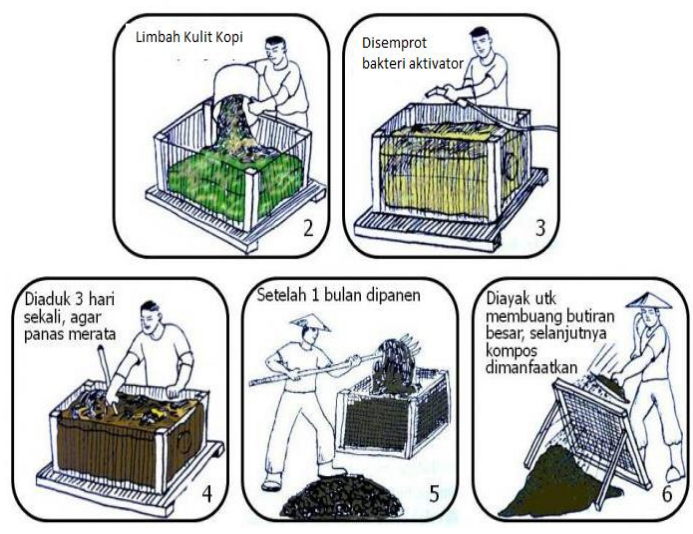

Gambar 1. Proses pembuatan kompos limbah kulit kopi (Yuwono, 2006).

\section{HASIL DAN PEMBAHASAN}

Pelaksanaan kegiatan pengabdian kepada masyarakat tentang biokonversi limbah kulit kopi menjadi pupuk kompos telah dilakukan dengan beberapa tahapan. Tahapan awal dari kegiatan adalah membuat rangkaian alat/media pengomposan dengan berbahan kayu (Gambar 2). Bahan ini dibuat dengan tujuan kemudahan dalam proses dan pengontrolan kondisi air dan udara dari kompos yang dibuat. Alternative media lain yang ditawarkan ke masyarakat adalah dengan menggunakan galian tanah, dengan menggunakan anyaman bambu atau paling sederhana menggunakan karung plastik. Media pengomposan ini dapat 
dipilih sesuai dengan kebutuhan dan kondisi di lapangan.
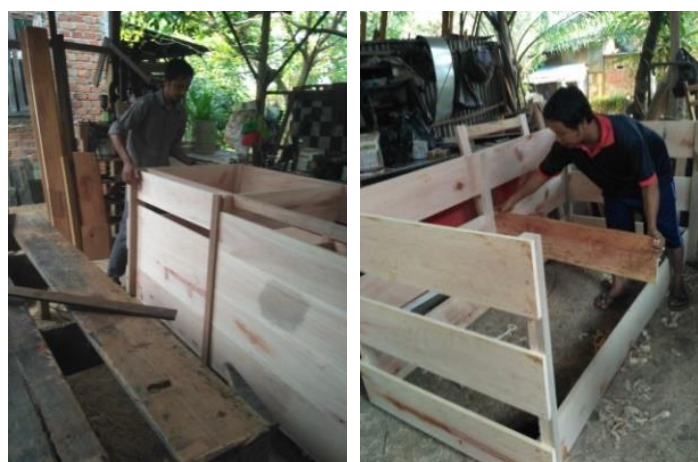

Gambar 2. Pembuatan Komposter

Setelah media dibuat, kegiatan dilanjutkan dengan sosialisasi dan penyampaian informasi dan pengetahuan kepada masyarakat tentang biokonversi limbah kulit kopi menjadi pupuk kompos. Penyampaian informasi dilakukan dengan metode ceramah dan pembagian leaflet tentang biokonversi limbah kulit kopi menjadi kompos dan dilanjutkan dengan diskusi dan tanya jawab seputar kegiatan. Pada saat kegiatan, penyampaian informasi dapat dilakukan dengan baik yang ditunjukkan dari antusias warga masyarakat untuk mendengarkan, berdiskusi dan bertanya. Tingkat pengetahuan awal (sebelum kegiatan) dari masyarakat secara umum belum mengetahui proses pembuatan kompos dari kulit kopi dan sebagian (2 dari 15 peserta) sudah/pernah mengetahui (Gambar 3). Setelah kegiatan sosialisasi, masyarakat sepenuhnya mengetahui proses pembuatan kompos dari kulit kopi yang meliputi bahan-bahan, serta proses pembuatannya.

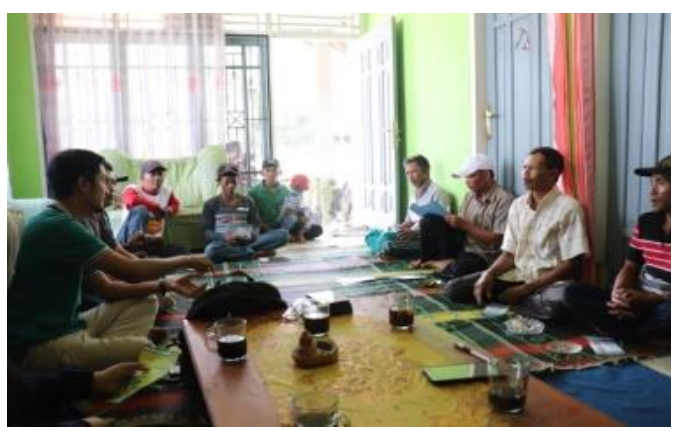

Gambar 3. Penyampaian Informasi tentang Biokonversi Limbah Kulit Kopi

Setelah masyarakat mendapatkan informasi tentang pengolahan limbah kulit kopi menjadi pupuk kompos, kegiatan dilanjutkan dengan kegiatan praktek pembuatan kompos dari limbah kulit kopi. Antusias masyarakat dapat dilihat dari semangat dan keingintahuan proses pembuatan kompos (Gambar 4).
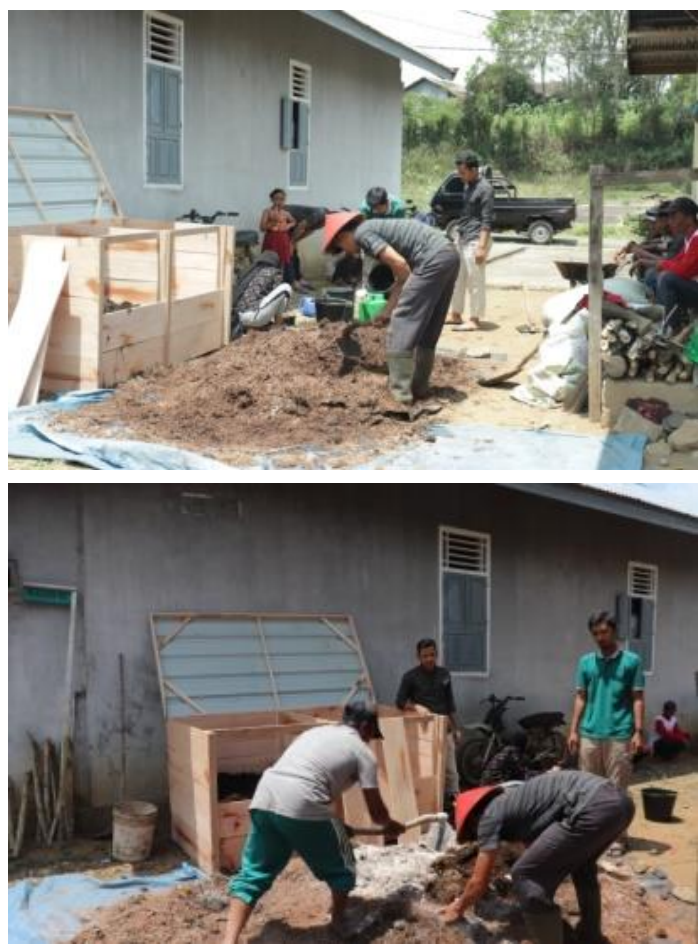


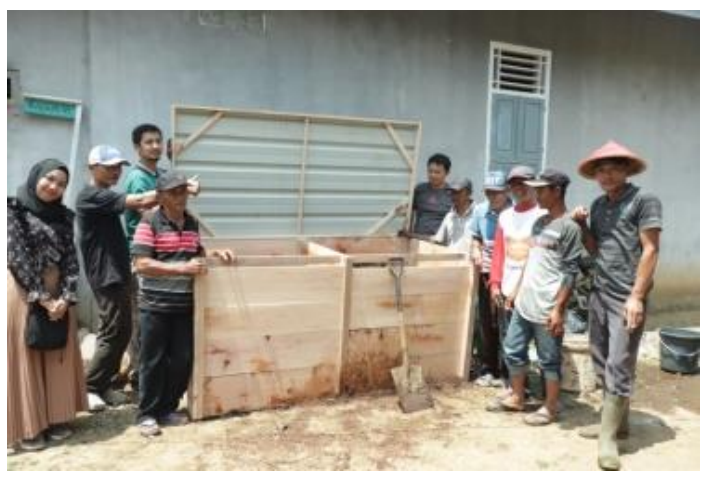

Gambar 4. Praktek Pembuatan Kompos dari limbah kulit kopi

Penyiapan bahan baku limbah kulit kopi, kotoran ternak dan bahan lainnya dilakukan oleh masyarakat langsung dengan tujuan masyarakat dapat lebih menyerap pengetahuan yang disampaikan. Ketersedian bahan baku kulit kopi sangan melimpah di lokasi pengabdian karena potensi kopi daerah ini cukup tinggi.

Hasil proses pembuatan kompos dari limbah kulit kopi dapat dilihat pada bulan kedua setelah kegiatan dilaksanakan. indikator terbentuknya pupuk kompos adalah warna kompos menghitam, tekstur yang lembut, mudah hancur dan rapuh (Gambar 5). Pupuk yang sudah jadi siap untuk diaplikasikan pada lahan kebun untuk berbagai jenis tanaman. Pada masyarakat kelompok tani Pangestu Rakyat, pupuk yang dihasilkan diaplikasikan ke lahan kebun kopi dan kebun sayuran.
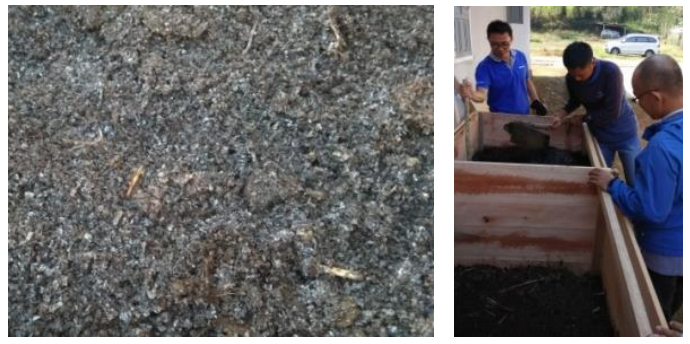

Gambar 5. Kompos yang sudah jadi dan siap digunakan

\section{KESIMPULAN}

Kegiatan biokonversi limbah kulit kopi menjadi pupuk kompos dapat meningkatkan pengetahuan dan tingkat inovatif masyarakat dalam pengolahan limbah rumah tangga sehingga dapat meningkatkan nilai guna dan nilai ekonomis dari limbah kulit kopi. Metode penyampaian informasi dan praktek langsung dinilai efektif dalam program ini dilihat dari tingkat inovasi masyarakat untuk mengolah limbah sayur dan bahan organik lainnya menjadi pupuk kompos sebagai tindak lanjut dari pupuk organik.

\section{UCAPAN TERIMAKASIH}

Penulis mengucapkan terimakasih kepada Universitas Bengkulu untuk pendanaan melalui dana PNBP UNIB Tahun 2019 dengan Nomor Kontrak 1551/UN30.15/PM/2019. 


\section{DAFTAR PUSTAKA}

Afrizon, 2015, Potensi Kulit Kopi Sebagai Bahan Baku Pupuk Kompos Di Propinsi Bengkulu, AGRITEPA, Vol. II, No. 1, Juli Desember 2015

Agus, C., Faridah, E., Wulandari, D.,Purwanto, B.H., Peran Mikroba Starter Dalam Dekomposisi Kotoran Ternak Dan Perbaikan Kualitas Pupuk Kandang., J. MANUSIA DAN LINGKUNGAN, Vol. 21, No.2, Juli 2014: 179-187

Antara Bengkulu, 2016, Produksi kopi Rejang Lebong Capai 13.402 Ton, edisi Selasa, 24 Mei 2016 14:38 WIB

Gaur, A.C. 1982. A Manual of rural composting. In Improving Soil Ferftility Through Organic Recycling. Project Field Document No. 15. Food and Agricultural Organization of The United Nation, Rome.
Hartatik, W \& Setyorini, D., 2012., Pemanfaatan Pupuk Organik untuk Meningkatkan Kesuburan Tanah dan Kualitas Tanaman., Prosiding Seminar Nasional Teknologi Pemupukan dan Pemulihan Lahan Terdegradasi., Hal. 571-582

Haug, R.T. 1980. Composting Engineering. Ann Arbor Science, Michigan.

Nurlianti \& Prihanani, 2018, Peran Decompeser Dalam Pembuatan Kompos Dari Limbah Padi Dan Limbah Sawit, JURNAL AGROQUA, Vol. 16 No. 1 Tahun 2018

Wandhira, A.W \& Mulasari, S.A., 2013, Gambaran Percobaan Penambahan Em-4 Dan Air Cucian Beras Terhadap Kecepatan Proses Pengomposan., Kurnal Kesehatan Masyarakat, Vol. 6/No. 2/2013: 101-112

Yuwono, D, 2006, Kompos, Jakarta : Penebar Swadaya 